\title{
Biomedical Applications of Shape Memory Alloys
}

\author{
Lorenza Petrini and Francesco Migliavacca \\ Politecnico di Milano, Laboratory of Biological Structure Mechanics, Department of Structural Engineering, \\ Piazza Leonardo da Vinci 32, 20133 Milan, Italy
}

Correspondence should be addressed to Lorenza Petrini, lpetrini@stru.polimi.it

Received 16 December 2010; Accepted 8 March 2011

Academic Editor: Stefano Gialanella

Copyright () 2011 L. Petrini and F. Migliavacca. This is an open access article distributed under the Creative Commons Attribution License, which permits unrestricted use, distribution, and reproduction in any medium, provided the original work is properly cited.

\begin{abstract}
Shape memory alloys, and in particular NiTi alloys, are characterized by two unique behaviors, thermally or mechanically activated: the shape memory effect and pseudo-elastic effect. These behaviors, due to the peculiar crystallographic structure of the alloys, assure the recovery of the original shape even after large deformations and the maintenance of a constant applied force in correspondence of significant displacements. These properties, joined with good corrosion and bending resistance, biological and magnetic resonance compatibility, explain the large diffusion, in the last 20 years, of SMA in the production of biomedical devices, in particular for mini-invasive techniques. In this paper a detailed review of the main applications of NiTi alloys in dental, orthopedics, vascular, neurological, and surgical fields is presented. In particular for each device the main characteristics and the advantages of using SMA are discussed. Moreover, the paper underlines the opportunities and the room for new ideas able to enlarge the range of SMA applications. However, it is fundamental to remember that the complexity of the material and application requires a strict collaboration between clinicians, engineers, physicists and chemists for defining accurately the problem, finding the best solution in terms of device design and accordingly optimizing the NiTi alloy properties.
\end{abstract}

\section{Introduction}

Nowadays, shape memory alloys (SMA), and in particular nickel-titanium alloys (NiTi), are commonly used in biomedical applications (see among others [1-7]). The main attractive features of this class of materials are the capabilities of: (1) recovering the original shape after large deformations induced by mechanical load (pseudoelasticity) and (2) maintaining a deformed shape up to heat induced recovery of the original shape (shape memory effect).

The explanation of these peculiar behaviors can be found in the crystallography and thermodynamics of SMA (see among others [8-11] and references therein). Indeed, SMAs are characterized by two solid phases: the austenitic phase $(A)$, which is stable at high temperatures $\left(T>A_{f}\right.$ austenite finish transformation temperature) and with high symmetry, and the martensitic phase, which is stable at low temperatures $\left(T<M_{f}\right.$ martensite finish transformation temperature, with $M_{f}<A_{f}$ ) and with low symmetry. In particular, the martensite can exist in two configurations: (i) the stress-free martensite, characterized by a twinned multivariant $(M)$ crystallographic structure, which minimizes the misfit with the surroundings (austenitic phase), hence not associated with any macroscopic deformation; (ii) the stress-induced martensite, characterized by a typical detwinned configuration with a single-variant $(S)$ crystallographic structure, which aligns variants along a predominant direction, hence associated with macroscopic deformation. The transformation between austenite and martensite is a stress-temperature induced athermal diffusionless thermoelastic martensitic transformation (TMT).

In particular, when the material is mechanically deformed at temperature greater than $A_{f}$, the stress induces the transformation from austenite to single variant martensite $(A \rightarrow S)$, once it has reached a value indicated in the following as $\sigma^{A S}$. Because the martensite is not stable for $T>A_{f}$, when the load is removed and the stress has reached the new value $\sigma^{S A}$, the inverse transformation $(S \rightarrow A)$ takes place and the material recovers the original shape. This peculiar behavior of SMA above $A_{f}$ (Figure 1) is the so-called 


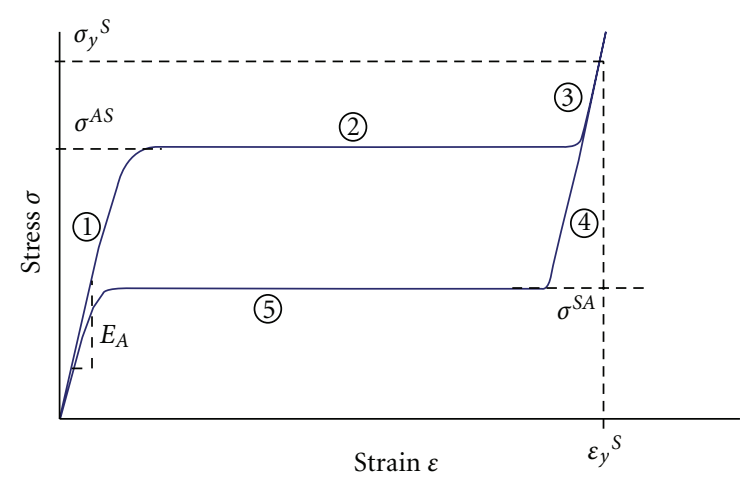

Figure 1: Pseudoelastic effect $\left(T \geq A_{f}\right)$. (1) Elastic deformation of austenite; (2) austenite to single-variant martensite transformation (upper plateau); (3) elastic deformation of single-variant martensite; (4) elastic strain recovery; (5) single-variant martensite to austenite transformation (lower plateau). $\varepsilon_{y}{ }^{S}=$ single-variant martensite yield strain (i.e., maximum elastic strain). $\sigma_{y}{ }^{S}=$ singlevariant martensite yield stress. $\sigma^{A S}=$ value of the stress component inducing $A \rightarrow S$ transformation. $\sigma^{S A}=$ value of the stress component inducing $S \rightarrow A$ transformation.

pseudoelasticity (PE). During loading-unloading, the material response shows a hysteretic cycle with $\sigma^{A S}>\sigma^{S A}$; when the direct and inverse transformations take place, the stress remains mainly constant over a wide range of deformation respectively at the upper and lower plateau (wide plateau). On the contrary, as the material is mechanically deformed at a temperature lower than $M_{f}$, a transformation from multivariant to single variant martensite $(M \rightarrow S)$ occurs once the stress has reached a value indicated in the following as $\sigma^{M S}$. When the stress is removed, a residual deformation takes place. Hence, heating the material above $A_{f}$ at zero stress allows the material to recover the residual strain: indeed, the single-variant martensite is no more stable at this temperature and the inverse transformation $(S \rightarrow A)$ takes place. The subsequent cooling below $M_{f}$ lets the material go back to the multivariant martensite configuration $(A \rightarrow$ $M)$ but without any macroscopic deformation. This peculiar behavior (Figure 2) is the so called shape memory effect (SME).

If boundary conditions do not allow the original shape recovery, the material is able to produce a high reaction based on the constraints: this phenomenon is called "constrained recovery" and is frequently used for generating forces in SMA devices. We notice also that the elastic modulus of the martensite $E_{M}$ is lower than austenite modulus $E_{A}$. This means that martensite can be deformed more easily than austenite.

Changing the alloy composition and performing thermomechanical treatment, it is possible to modify the characteristic parameters of SME and PE behaviors, such as the maximum thermally recovering strain, the TMT characteristic temperatures, and the hysteresis properties. Ad hoc thermomechanical treatments (training effect) allow the material to memorize two different shapes, thereby allowing a stable configuration in the austenitic and martensitic phase,

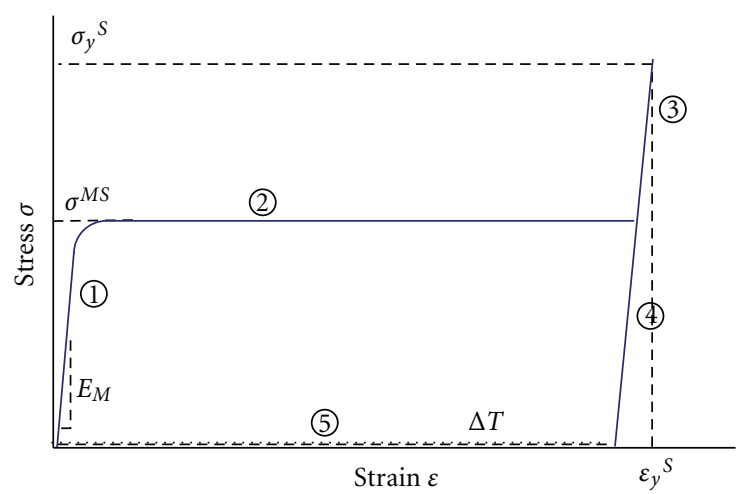

Figure 2: Shape memory effect $\left(T \leq M_{f}\right)$. (1) Elastic deformation of multivariant martensite; (2) multivariant to single-variant martensite transformation; (3) elastic deformation of single-variant martensite; (4) elastic strain recovery; (5) transformation strain recovery by thermal loading $\Delta T$ which increases the temperature up to $A_{f} \cdot \varepsilon_{y}{ }^{S}=$ single-variant martensite yield strain (i.e., maximum elastic strain). $\sigma_{y}{ }^{S}=$ single-variant martensite yield stress. $\sigma^{M S}=$ value of the stress component inducing $M \rightarrow S$ transformation.

respectively. Temperature cycles between $A_{f}$ and $M_{f}$ involve changes between the two shapes. This is the so called "two way shape memory effect." Although it is a very interesting effect, it is nowadays rarely used because of the difficulty in performing a correct training and the memory loss due to the increasing number of cycles.

\section{The Nickel-Titanium Alloy}

Within the wide family of shape memory alloys (AgCd, AuCd, CuAlNi, CuAlBe, CuSn, CuZn, InTl, NiAl, FePt, $\mathrm{FePd}, \mathrm{MnCu}, \mathrm{FeMnSi}$ ), NiTi-based alloys (with 48-52\% in weight of $\mathrm{Ni}$ ) associate shape-memory and pseudoelastic effects, which are characterized by large plateau and stress hysteresis, with good workability in the martensite phase and good resistance to corrosion and fatigue [12]; accordingly, nowadays most of SMA devices are produced with these alloys. Their use in biomedical applications is also suggested by their good biocompatibility [13-15] and excellent magnetic resonance and computer tomography compatibility [16]. Moreover, the mechanical behavior of $\mathrm{NiTi}$ is more similar to biological tissue response [17] if compared with that of other metallic materials commonly used for biomedical devices, as stainless steel $316 \mathrm{~L}$ and chromium-cobalt (Cr-Co) alloys. This is also shown in Table 1, reporting some selected physical and mechanical properties that are typical of annealed tubing materials for vascular stent application [18]. The device production procedure may strongly influence material characteristics; for this reason it is important to specify for which application the material is prepared. The collected data highlight the NiTi lower stiffness (around 1/4 of other material stiffness) and wider range of elastic behavior (the linear behavior finishes when $A \rightarrow S$ transformation starts, but yielding takes place when single-variant martensite yield strain is reached). 
TABLE 1: Selected physical and mechanical properties typical of annealed tubing materials for vascular stent application. UTS $=$ ultimate tensile stress; UTE = ultimate tensile strain. For the meaning of $\sigma^{A S}$ and $\varepsilon_{y}{ }^{S}$, see Figure 1.

\begin{tabular}{lcccccc}
\hline Alloys & Specific mass $\left(\mathrm{g} / \mathrm{cm}^{3}\right)$ & Elastic modulus $(\mathrm{GPa})$ & Yield stress $(\mathrm{MPa})$ & Yield strain $(\%)$ & UTS $(\mathrm{MPa})$ & UTE $(\%)$ \\
\hline 316 L & 7.95 & 193 & 340 & 0.17 & 670 & 48 \\
ELGILOY & 8.30 & 221 & 450 & 0.20 & 950 & 45 \\
NiTi & 6.45 & $E_{A}=53.5 E_{M}=29.2$ & $\sigma^{A S}=400$ & $\varepsilon_{y}{ }^{S}=9.0$ & 1355 & 14.3 \\
\hline
\end{tabular}

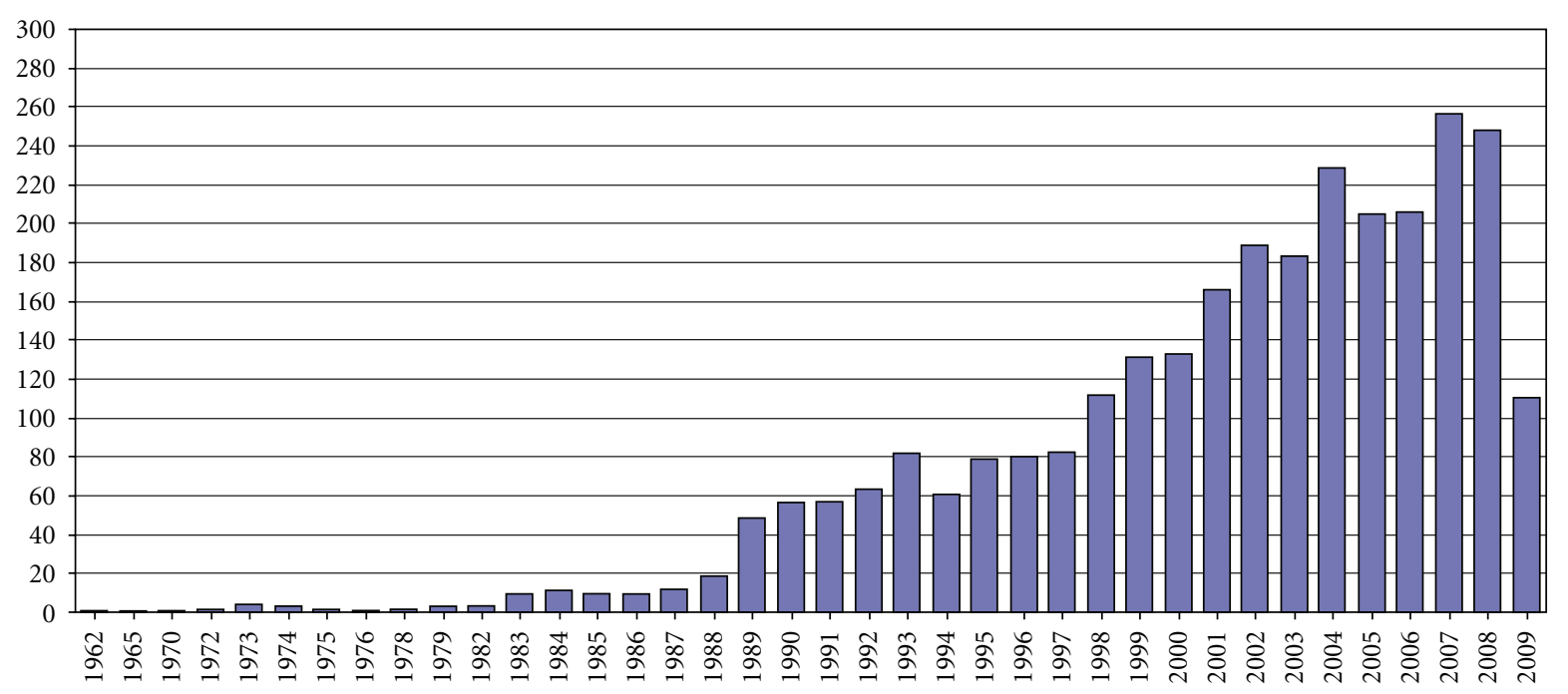

FIgURE 3: Number of publications per year.

The plateau stress is comparable with the yield strength of other materials; however, at ultimate condition, NiTi stress is higher but strain is significantly lower than the others. This is probably due to the fact that NiTi remains strongly work hardened even after annealing.

An interesting fact surfaced during a patent research performed by the Technology Transfer Office of Politecnico di Milano by way of using the "QPAT" database and referring to the most significant International Patent Classification (IPC) codes for the biomedical field. The results of this search show that there are more than 2900 inventions with the text strings "shape memory alloy or alloys," "shape memory or memorizing material" "shape memory device or devices," "SMA," "NiTi," and "Nitinol" (in the title, in the abstract, or in the independent claim). In Figures 3 and 4 the queries published from 1962 to June 2009 are presented (publications take place 18 months after the deposit) and the countries where the invention was extended, respectively. In Figure 5, the countries where the priority query was deposited are reported. The results underline a growing patent activity; in particular a period of strong publication has been started from 2000. From the 60's the countries more active have been USA and Japan while China has intensified its activity in the last 5 years. It is interesting to notice that most of the patents are then extended to the world or to Europe. Figure 6 presents the first 50 patent holders: most of the companies are American or Japanese.

In Table 2, the main NiTi biomedical devices are reported, distinguishing them on the basis of the exploited effect
(PE or SME) and application fields: dental, orthopedics, vascular, neurological, surgical, and others fields. In the following sections, the different applications will be discussed in detail.

\section{SMA Applications in the Orthodontic Field}

The first application of NiTi in the biomedical field dates back to 1975 when Dr. Andreasen from Iowa University made the first implantation of an orthodontic device exploiting the pseudoelastic property of the alloy [19]. NiTi wires, which are in austenitic phase at the temperature of the buccal cavity, have been successfully used for years in fixed orthodontic treatment with multibrackets [20], Figure 7. In particular, pseudoelasticity is exploited for generating constant force, after positioning of the wire into the brackets, for wide dental movements. During the insertion phase, the physician deforms the wire thereby inducing a transformation phase from austenite to single-variant martensite (Figure 1: steps (1) and (2)); once positioned, the material tries to go back to austenite phase (stable at the buccal cavity temperature) and hence tries to recover the original shape following the descendent path of the force-displacement curve in austenitic phase, which is characterized by a wide plateau (Figure 1: steps (4) and (5)).

The shape memory effect, and in particular the "constraint recovery" effect, is exploited for producing wires that are in martensitic phase during the positioning into the buccal cavity: deformed during the insertion into brackets, 


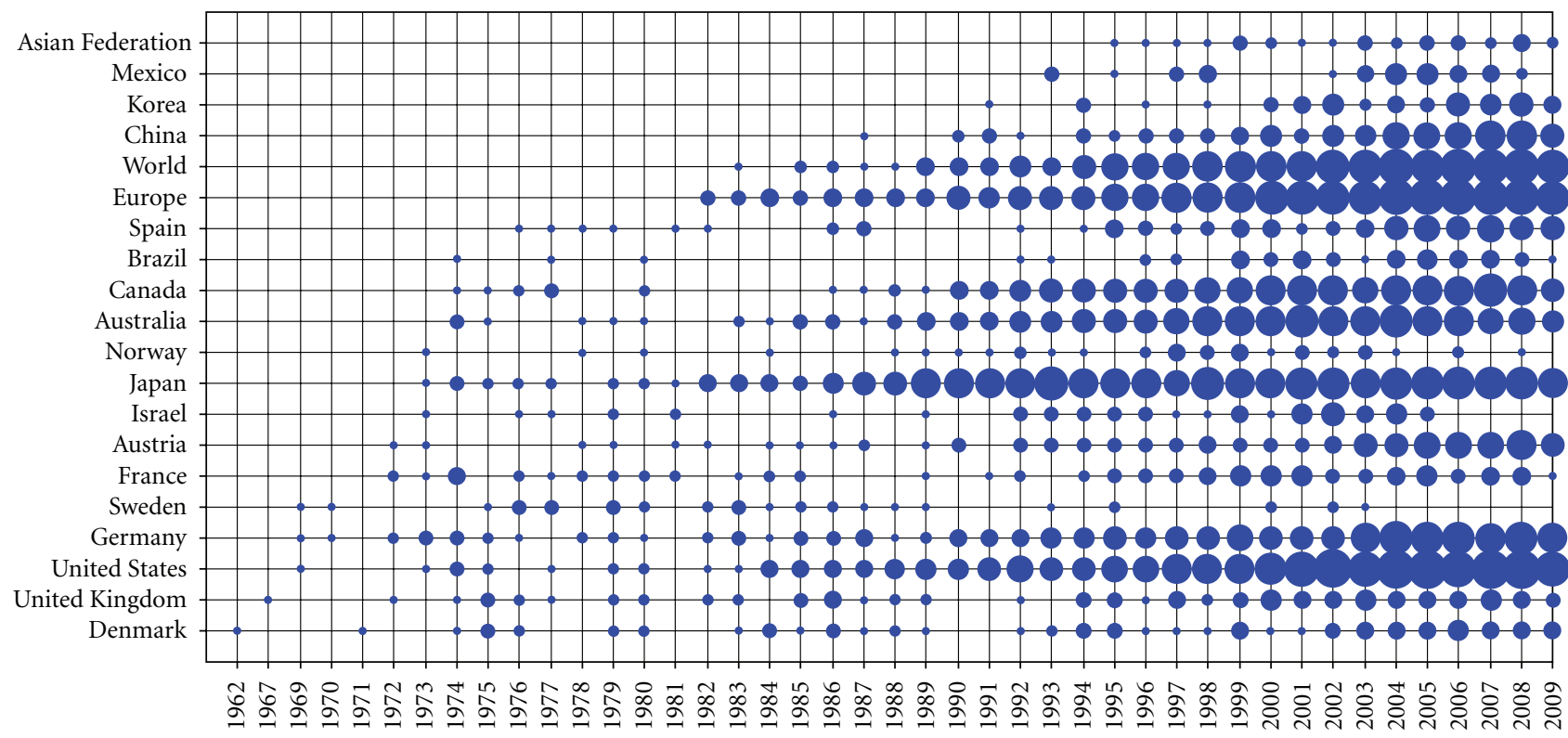

FIGURE 4: Geographic distribution according to the country of deposit.

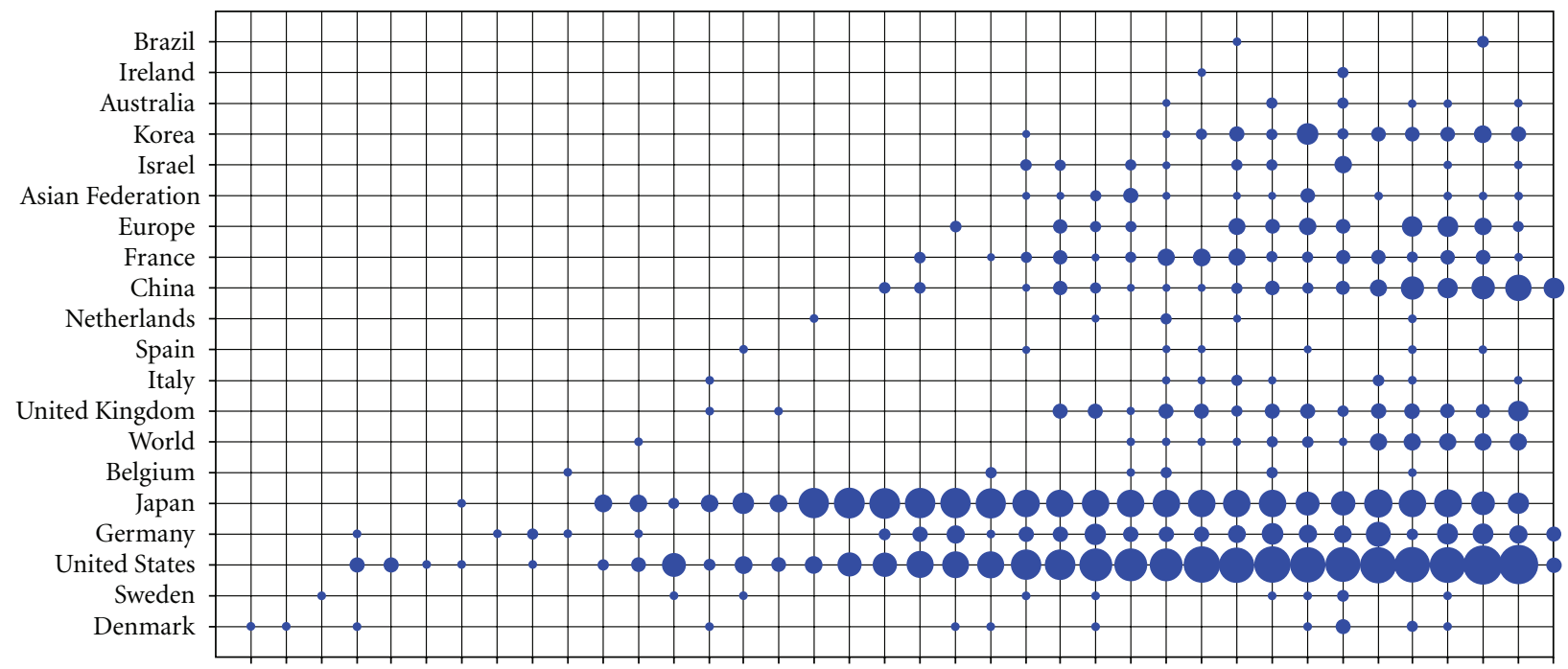

。

FIGURE 5: Geographic distribution according to priority.

they try to recover the original undeformed shape whenever the patient ingests hot food or drinks. Because the recovery is prevented, the wires exert light forces on the teeth for the entire period in which the temperature is above the normal values [21].

SMA wires are also inserted into steel palatal arches (Figure 8(a)); a palatal arch is mounted on superior molars and applies rotating, expanding and torquing forces. The presence of parts made by SMA exploiting pseudoelasticity allows the device to apply lighter (with respect to the forces generated by an arch completely in steel) and constant forces. Pseudoelastic behavior is also exploited for producing orthodontic distractors [22] (Figure 8(b)), which are used for solving the problem of teeth overcrowding in the mandible district: after a mandibular symphyseal distraction osteogenesis, the device is applied in order to produce an expansion of the mandible. Also in this case the use of SMA assures tensile forces nearer to the physiological values and constant in time. These forces create stress conditions that improve the tissue growth and hence teeth movement into the correct position.

In the endodontic field (the dentistry branch that studies the problems related with the tooth pulp and the tissues surrounding the root of a tooth), the medical treatment foresees the use of rotating devices (files) working inside the root canal to perform a perfect cleaning and shaping: the decontaminated canal is then filled with an inert filling. 


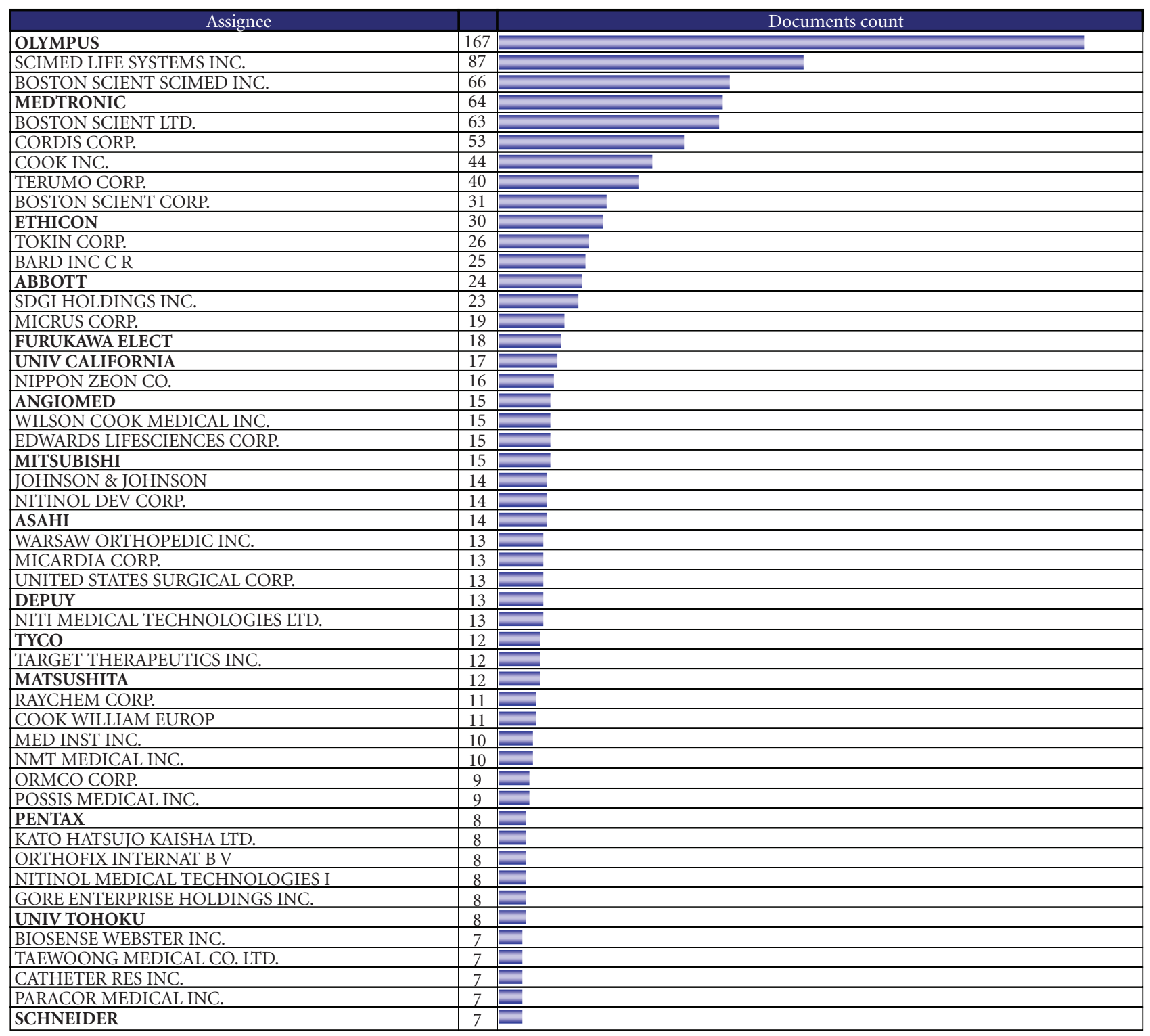

Figure 6: First 50 patent holders.

TABLE 2: Sketch of the main NiTi applications in the biomedical field according to SMA properties.

\begin{tabular}{lll}
\hline & $\begin{array}{l}\text { Pseudoelasticity } \\
\text { Mechanical shape recovery/wide plateau/constrained } \\
\text { recovery }\end{array}$ & $\begin{array}{l}\text { Shape Memory Effect } \\
\text { Heat-induced shape recovery/constrained } \\
\text { recovery }\end{array}$ \\
\hline Orthodontic field & Wires, palatal arches, distractors, endodontic files & Wires \\
Orthopedic field & Intraspinal implants, intramedullary nails & $\begin{array}{l}\text { Staples or plates, devices for correcting scoliosis, } \\
\text { spinal vertebrae spacer, intramedullary nails, } \\
\text { devices for physiotherapy }\end{array}$ \\
Vascular field & $\begin{array}{l}\text { Venous filters, devices for closing ventricular septal } \\
\text { defects, self-expandable vascular stents, stent-graft, } \\
\text { percutaneous devices to treat valvular diseases } \\
\text { Coils, stents, microguidewires }\end{array}$ & $\begin{array}{l}\text { Venous filters, devices for closing ventricular } \\
\text { septal defects }\end{array}$ \\
$\begin{array}{l}\text { Neurosurgical Field } \\
\text { Surgical field }\end{array}$ & & \\
\hline
\end{tabular}




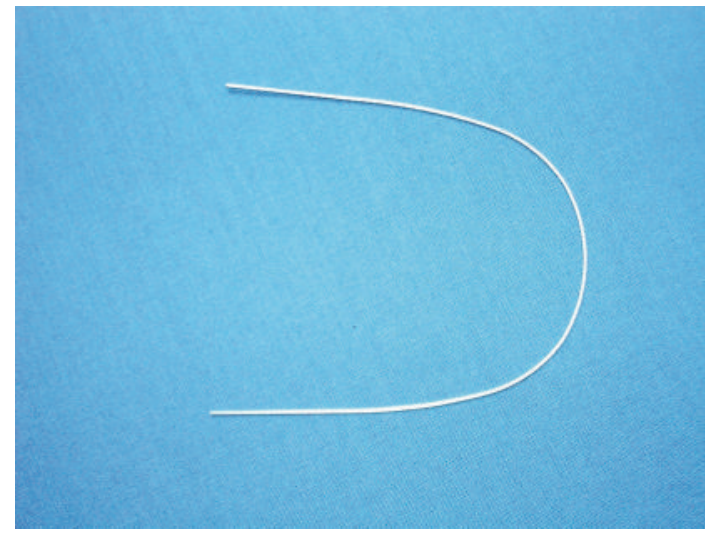

(a)

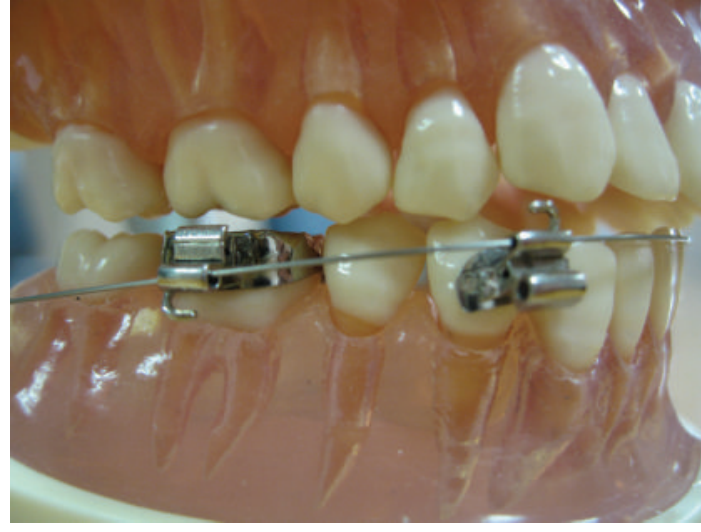

(b)

FiguRE 7: SMA orthodontic wires.

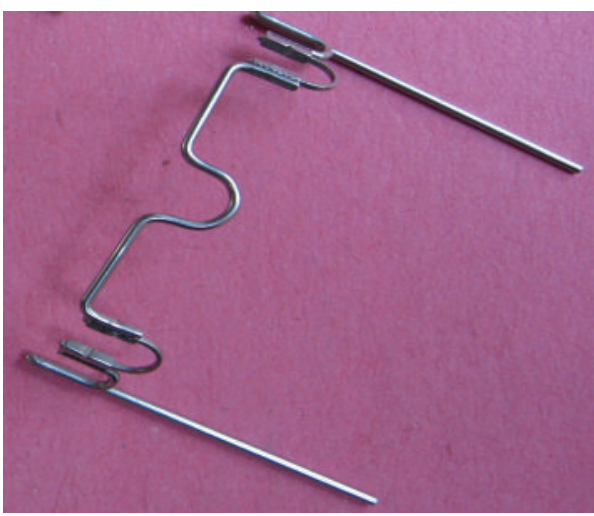

(a)

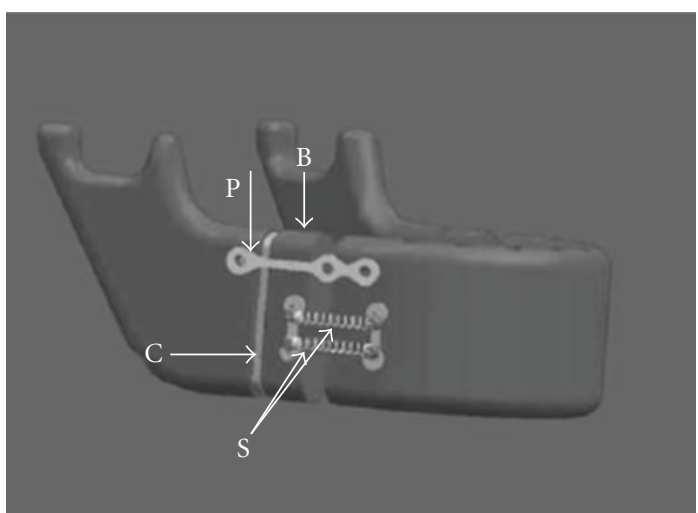

(b)

FIgURe 8: (a) Palatal arch. (b) Orthodontic distracters [22].

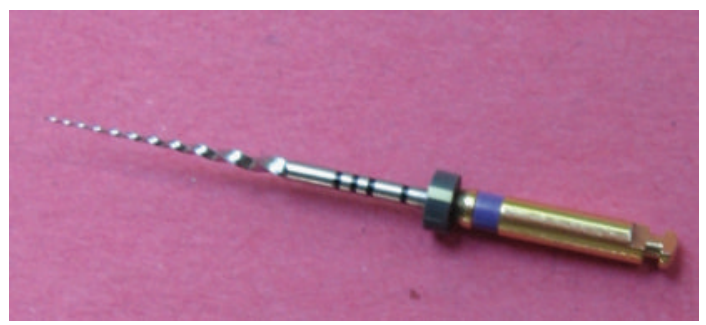

FIGURE 9: Endodontic file.

The files must have good flexibility and a cutting blade. The first devices were from steel and used manually. At the end of the 80 's, a great improvement in the technique was given by the introduction of NiTi $[23,24]$ : the pseudoelastic behavior assured a high flexibility, recovery of deformation (without production of plastic strain), and limitation of the applied force, thus allowing the use of NiTi files (Figure 9) with a rotating motor [25].

\section{SMA Applications in the Orthopedic Field}

The stress generated by SMA, when the shape recovery is constrained during heating from $M_{f}$ to $A_{f}$, is exploited for fracture treatment by using orthopedic staples [26] or plates. The device (Figure 10), characterized by a temperature $A_{f}$ lower than that of the body, is deformed in the martensitic phase $\left(T \leq M_{f}<A_{f}\right)$ and hence inserted into the body where the fracture is present. The body temperature induces the shape memory effect; because of the constrained recovery, the plates induce a constant stress, consequently joining the two fractured pieces. In Figure 11(a), an application for the treatment of mandible fracture is reported [27].

NiTi rods are also inserted in devices for correcting scoliosis [28-30]; in this case, the constrained recovery is used for modifying vertebrae relative position. It has also been proposed [1] to exploit the shape memory effect (Figure 2) for designing a spinal vertebrae spacer with a rounded shape to be used on behalf of the damaged intervertebral disc. By exploiting the material's high deformability in martensitic phase, it is possible to modify the device shape for facilitating the insertion between the vertebrae where, being that 


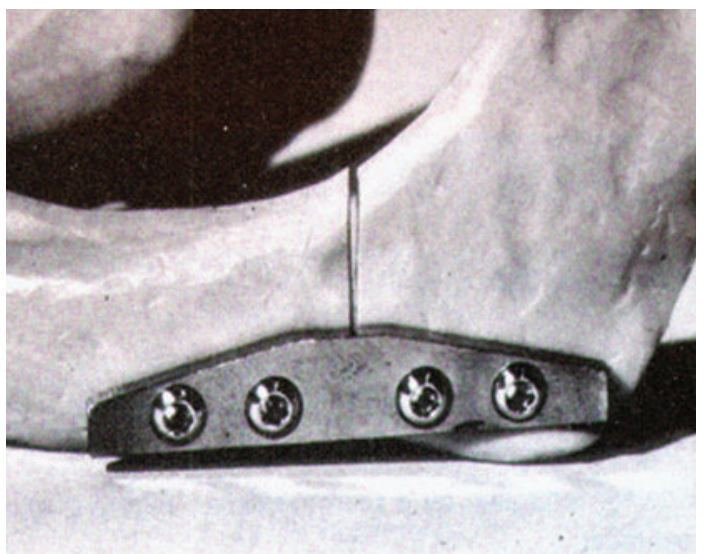

(a)

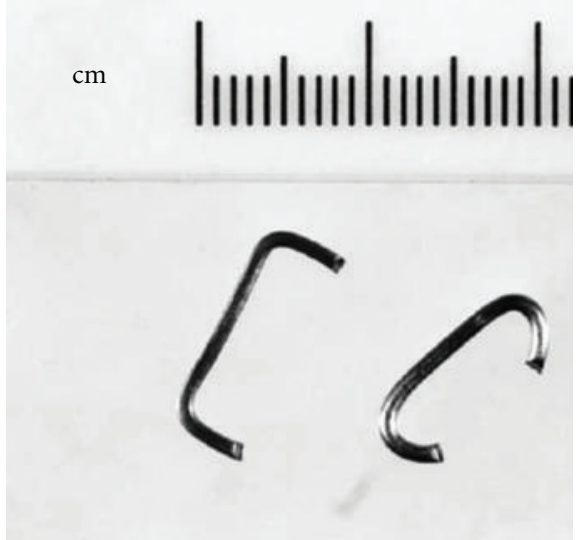

(b)

Figure 10: (a) NiTi plate for mandible fracture [1]; (b) staple before and after distraction [27].

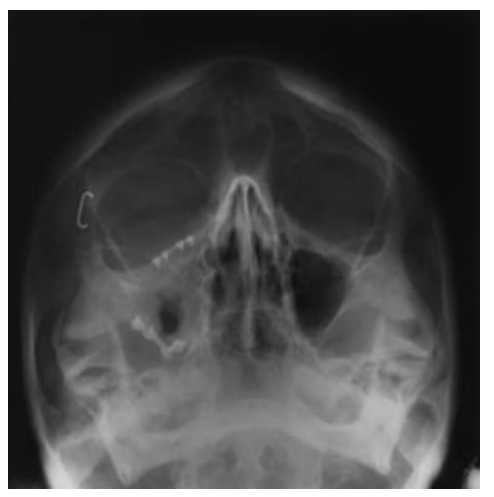

(a)

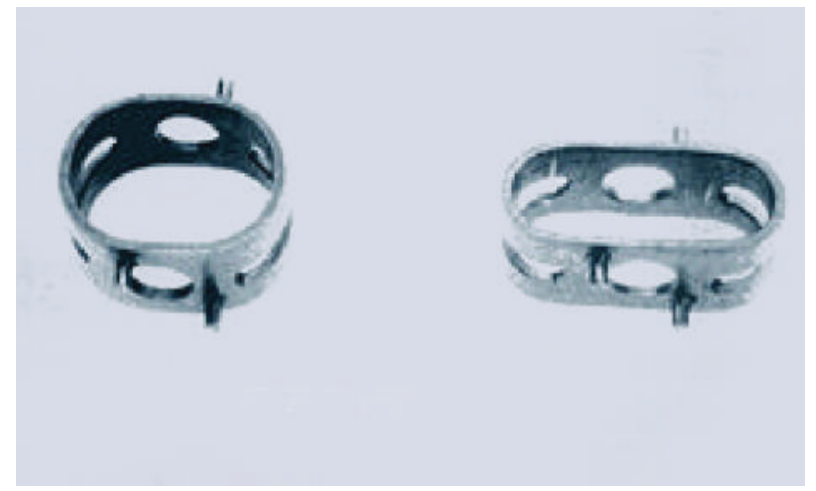

(b)

FIGURE 11: (a) staple for fixing a frontozygomatic fracture [27]; (b) spinal vertebrae spacer [1].

the temperature is higher than $A_{f}$, the device recovers to its original shape (Figure 11(b)). Recently, intraspinal implants exploiting pseudoelasticity have been studied for stabilizing spinous processes in the case of vertebral discs [31].

The pseudoelastic effect is also exploited in the production of NiTi intramedullary nails [32]. In a recent patent [33], the two-way shape memory effect is used for inserting and subsequently removing the intramedullary nail in fractured elongate bones. As shown in Figure 12, the nail shows some SMA elements positioned along the stem in suitable seats. These elements can, by way of varying the temperature, assume two different configurations: an open position, where they stick out of the stem, and a closed position where they are retracted in the stem. The first configuration is used during insertion and extraction while the second position is induced during the fracture treatment for fixing the nail to the bone. The patent suggests to have a temperature $A_{f}$ lower than body temperature: in this way, in the open position the material is in the austenitic phase while the closed position, corresponding to the martensitic phase, is induce by cooling the device down to a suitable temperature $T<M_{f}<A_{f}<$ $37^{\circ} \mathrm{C}$.
In orthopedics treatments, the SMA properties are also exploited during the physiotherapy of partially atrophied muscles [34]. Gloves for promoting the movements of hands were developed by positioning SMA wires in correspondence of the fingers. In this application the two-way shape memory effect is exploited; heating or cooling, the wires contract or stretch and accordingly the hand is closed or opened (Figure 13).

Another recent application of SMA in the orthopedic field refers to SMA foams. Porous NiTi, characterized by low density, high surface area, high permeability, high strength (important to prevent deformation or fracture), relatively low stiffness (useful to minimize stress shielding effects), high toughness (essential to avoid brittle failure), and by a shape-recovery behavior (facilitating implant insertion and ensuring good mechanical stability within the host tissue), is particularly interesting for osteointegration processes.

Notwithstanding a porous form of NiTi was discovered at the end of the 60's [35] and immediately the high potentialities were recognized, the effective use of NiTi foams (Figure 14) started only recently after deep studies of biocompatibility and corrosion resistance [36-38]. From these 
studies, the importance of the fabrication processes for creating foams with desirable architectures and microstructures, and of the pore surface modifications for tailoring the biological interactions was underlined. Among the principal applications [39], we recall the devices for spinal fusion: a device for lumbar and cervical vertebrae is available on the market since 2002 (Actipore of Biorthex, Canada). It was verified [40] that porous NiTi gave a higher stimulus for bone tissue growth and a bone deposit velocity two orders higher than traditional materials (titanium, stainless steel, chromium-cobalt). We expect that in the next feature further applications of porous NiTi also exploiting pseudoelastic or shape memory effect will be developed.

\section{SMA Applications in the Vascular Field}

Besides the orthodontic field, the SMA devices are broadly applied in the vascular one. In particular, the introduction of the shape memory alloys boosted the development of mini-invasive techniques where the pathology is treated by the percutaneous insertion of the device rather than surgical intervention.

The first vascular SMA application was the venous "Simon filter" (Figure 15(a)) used to prevent emboli in patients unable to tolerate anticoagulants. It can be inserted thanks to the shape memory effect [41-44]. The device is produced in the open configuration with a NiTi alloy having $A_{f}$ equal to the body temperature, which depicts it in the martensitic phase at ambient temperature. Thus, during the crimping of the device on the catheter, a residual deformation is present as-consequence of the martensitic transformation from multivariant to single-variant phase, which allows the device to be closed and easily placed in the catheter. A saline solution flows in the catheter to keep the temperature low during its insertion into the body. When the catheter is in position, the filter is released, the saline solution is stopped and the body heat induces the martensite-austenite transformation with recovery of the device's original shape. The filter is now able to block the possible clots of the blood stream. In literature, it is possible to find a variety of different filters $[45,46]$ which use the pseudoelastic effect; similarly in this situation, the open configuration at ambient temperature is already in a stable austenitic phase; the crimped device, as soon as it is released in the body, recovers to its original open configuration.

Other common devices are those used to close ventricular septal defects [47-49], which are characterized by the presence of an atrial hole in the surface between the two lowpressure chambers of the heart. The surgical method includes an invasive and hazardous approach via a thoracotomy and manual suture of the hole. The alternative of using a mini-invasive approach is appealing. The device is made of SMA wires and of an impermeable polyurethane membrane (Figure 15(b)). The insertion procedure consists of three steps: (i) positioning of the catheter with the crimped device through the superior vena cava, (ii) positioning of the catheter tip in the left atrium and release of half of the device, and (iii) completion of procedure via release of the remaining

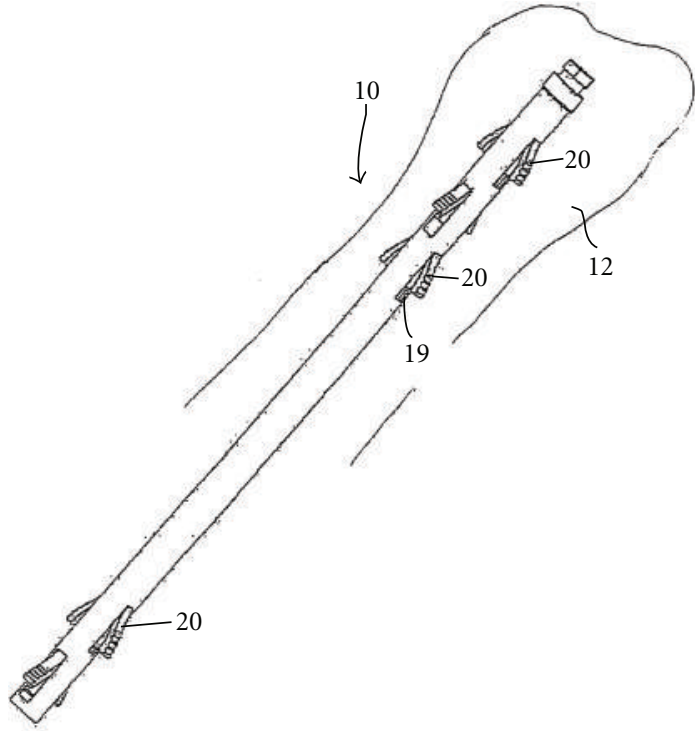

FIGURE 12: Intramedullary nail for fractured elongate bones [33].

part of the device in the right atrium. According to the device typology, both shape memory and pseudoelastic effects are utilized.

NiTi alloys are also used in numerous applications of the self-expandable vascular stents. Stents are metallic "nets" (built by means of laser cutting stainless steel, Cr-Co, or NiTi alloy tubes) which open a stenotic vessel (obstructed by atherosclerotic deposits), therefore allowing restoration of the blood stream to peripheral tissues [50-52]. For the stainless steel and $\mathrm{Cr}-\mathrm{Co}$ alloy stents, the stenting procedure consists of: (i) crimping the stent in the terminal part of a catheter which has an inflatable balloon, (ii) insertion of the catheter through a surgical incision in a vessel and positioning of the catheter through the vessel in the stenotic region, (iii) inflation of the balloon with expansion of the stent which pushes against the arterial vessel and (iv) deflation of the balloon and removal of the catheter. Following elastic recoil, the stent remains in an open configuration (plastic deformation) and counteracts the natural vessel contraction, which would tend to reocclude the vessel. For the NiTi stent, the stenting procedure consists of: (i) crimping the stent into the catheter in the austenitic phase $\left(A_{f}\right.$ is lower than body temperature) by means of a protective sheath, (ii) insertion of the catheter as stated above and (iii) removal of the sheath and expansion of the stent which tries to recover its original shape thereby enlarging the stenotic vessel. During this phase, the inverse transformation from martensite to austenite occurs, which is due to the martensitic instability at a temperature higher than $A_{f}$. The advantage of the selfexpandable stent with respect to the stainless steel one is that it does not need balloon expansion which possess the risks of further damage of the vascular tissue due to its inflation, it does not require an overexpansion to account for the elastic recoil, and, when positioned, it exerts on the artery a constant force (due to the plateau) unless the artery does not try to occlude the device. The disadvantage, in case of calcified 


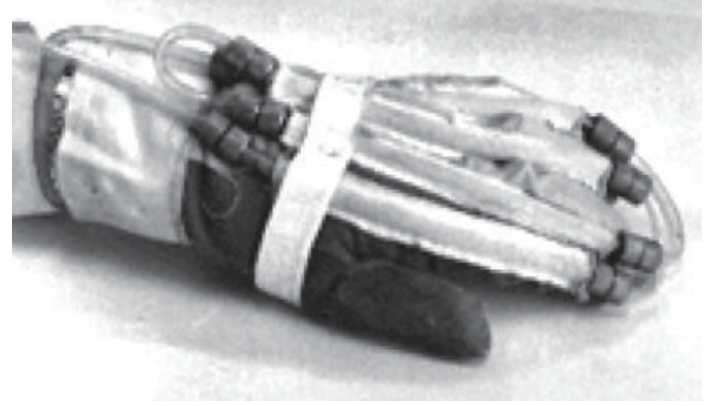

(a)

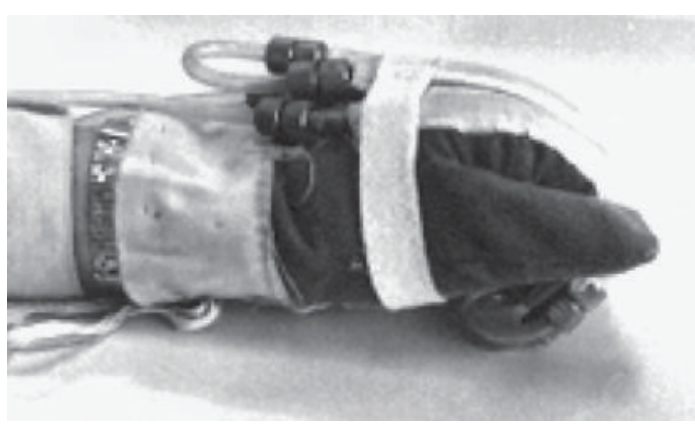

(b)

FIGURE 13: Gloves with SMA wires [34]: (a) position at low temperature; (b) position at high temperature.

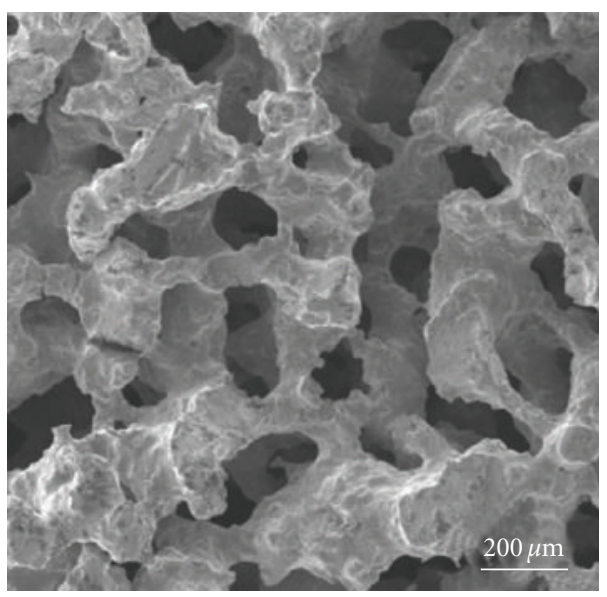

(a)

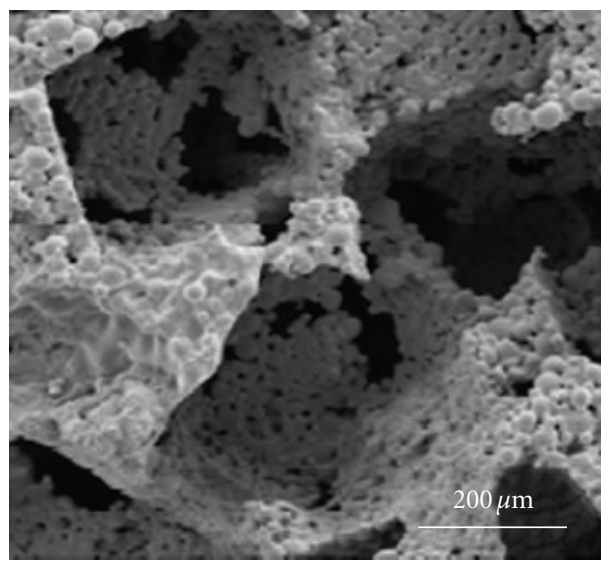

(c)

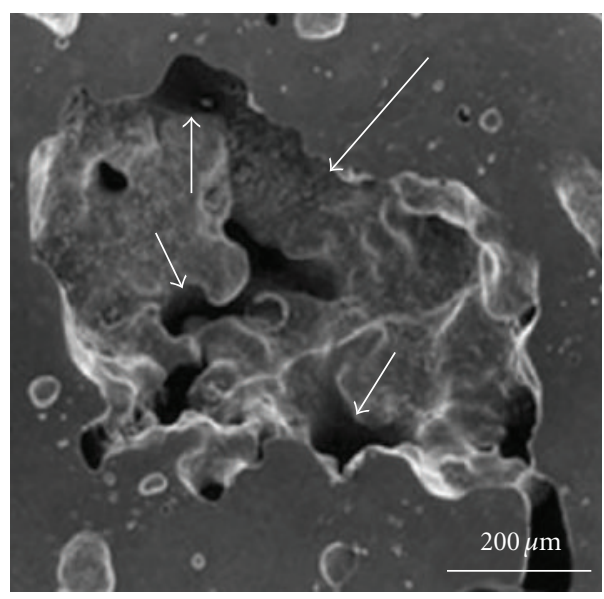

(b)

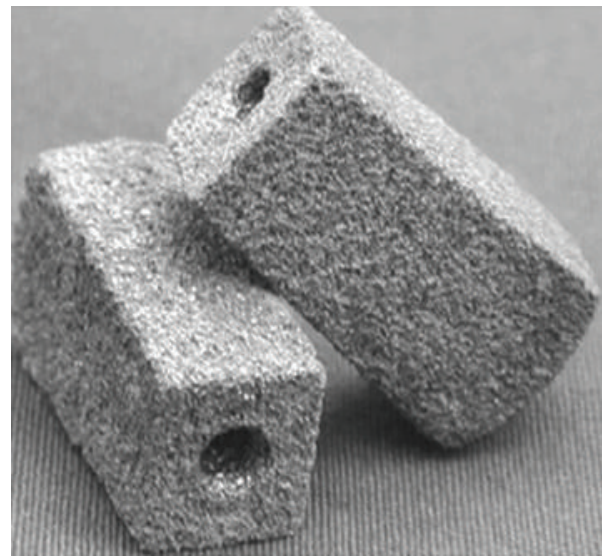

(d)

FIGURE 14: Scanning electron microscope images of porous NiTi produced using three different methods: (a) self-propagating hightemperature synthesis process (porosity $65 \pm 10 \%, 100-360 \mu \mathrm{m}$ ) (b) capsule-free hot isostatic pressing with argon expansion (porosity $42 \%$, 50-400 $\mu \mathrm{m}$ ) (c) metal injection molding (porosity 70\%, 355-500 $\mu \mathrm{m}$ ). (d) Commercial porous NiTi implant (Actipore, Biorthex, Canada) for spinal fusion produced by SHS process [38].

plaques, is that the stent is not able to bring the vessel lumen to the original healthy dimensions. Self-expandable stents are used to treat atherosclerotic lesions in the coronary arteries, the carotid arteries, and in the peripheral arteries, such as the iliac [53] and femoral arteries (Figure 16). The pseudoelasticity property is very important in the peripheral stent which is subjected to possible squeezing manoeuvres such as muscle contractions.

Another successful application of the NiTi alloys is the use of the stent-graft for the treatment of abdominal aortic aneurisms (AAA) [54-56]. An aneurism is a permanent dilatation of a portion of an arterial vessel because of vessel 


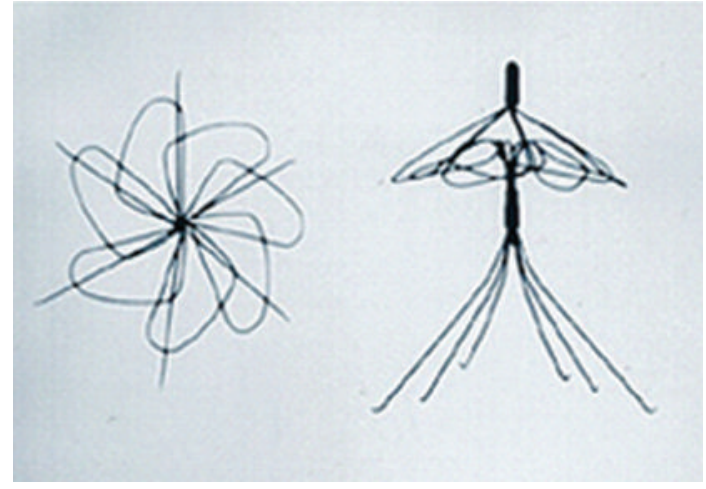

(a)

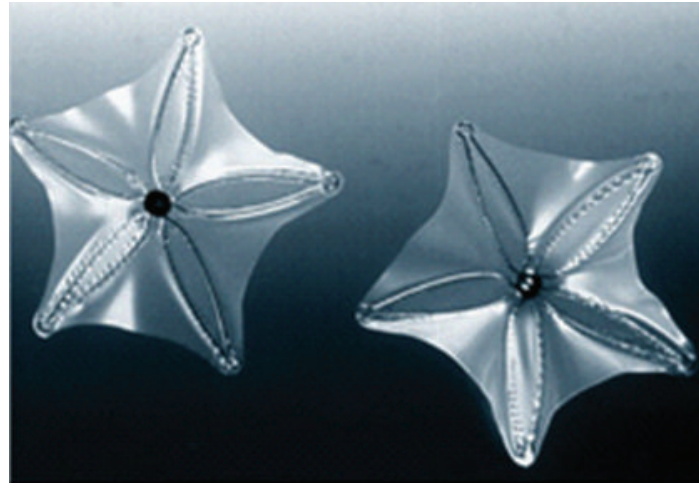

(b)

Figure 15: (a) Venous filter: Simon filter; (b) device to close ventricular septal defects.

wall alterations. For the treatment of this pathology, in the last years, in conjunction with classical surgical techniques, endovascular techniques, with the percutaneous insertion of stent-graft, gained popularity. This means that the stentgraft is easily crimpable on a catheter, sufficiently flexible during the insertion phase, and able to recover its original shape anchoring to the aorta once it has been positioned correctly. All of these features are present in the pseudoelastic behaviour of the NiTi alloys. This is an explanation of the numerous different prostheses present on the market [57] (Figure 17).

A recent and very promising field of SMA application is related to the stenotic and regurgitant cardiac valves [58]. The common adopted strategy to overcome this pathology consists of surgical valve replacement with a mechanical or biological valvular prosthesis. A thoracotomy is present in this substitution eliciting possible surgical complications. The use of mini-invasive techniques allows the surgeon to reduce, in a significant way, the risks of the procedure. For this reason, there are different companies which are developing percutaneous devices to treat mitral, pulmonary, and aortic valvular diseases. For the aortic position, for example, CoreValve developed a device (Figure 18(a)) which consists of a biological prosthesis made with bovine pericardium mounted and sutured on a self-expandable stent [59]. The insertion procedure consists of positioning the device with a specifically designed catheter without the need for removal of the native valve. The self-expandable stent shows a diamond-like cell design with struts at different lengths and thicknesses to optimise the expansion to a nonregular shape (Figure 18(b)). It is interesting to observe the stent shape obtained from a laser-cut NiTi tube: the superior part (highly expanded) allows for the anchoring of the prosthesis to the aortic walls; the central portion supports the valves, which in turn determines the diameter; the inferior part anchors the prosthesis to the aortic annulus eliminating migration problems thanks to its high radial force.

A different solution for the endovascular treatment of the aortic valve [60] is the use of a prosthesis where the valve is manufactured with $10 \mu \mathrm{m} \mathrm{NiTi} \mathrm{membranes} \mathrm{and} \mathrm{the} \mathrm{stent}$ exploits the pseudoelastic properties of the SMA (Figure 19).

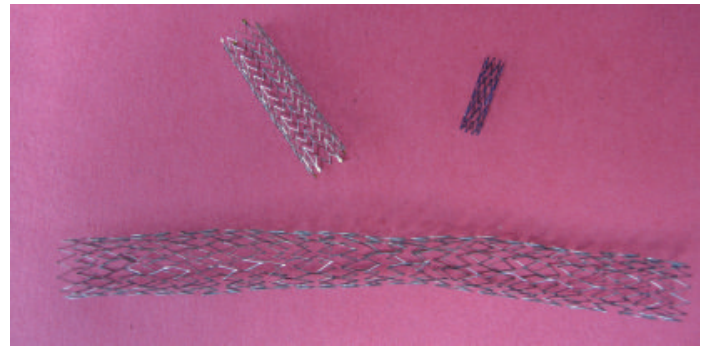

FIGURE 16: Example of SMA stents: (top right) coronary stent, (top left) carotid stent, (bottom left) femoral stent.

These membranes called "eNitinol" are sufficiently flexible to be used as leaflets in a semilunar valve and are designed to behave as a scaffold for the endothelial cells: the membranes allow long life as a mechanical valve, but without the necessity of anticoagulant therapy. Furthermore, the use of a SMA membrane allows reduction of the overall dimensions of the prosthesis in a significant way.

In the last years, the ever more extended use of NiTi in cardiovascular applications has pointed out the problem of its fatigue behaviour [61]. In particular, for the treatment of peripheral arterial diseases with self-expandable stents, there is a growing concern about observations of fractures during follow-up procedures [62]. Fractures are mainly detected in superficial femoral artery and femoropopliteal arteries. This is probably related to the combination of pulsatile forces, due to systolic/diastolic pressure cycles, and nonpulsatile forces (torsion, compression, extension, and flexion), due to leg movements, which characterize the stent solicitations. The study of NiTi fatigue life is a current and very complex problem [63]: the nonlinear nature of the pseudoelastic behaviour entails that conventional fatigue life theory is difficult to apply; the strong influence of the production treatments on the material characteristics requires fatigue specimens having the same dimensions and production treatments of the device under study; design, material, and surface conditions together play an important role for the definition of NiTi alloy stent fatigue and durability. For all 


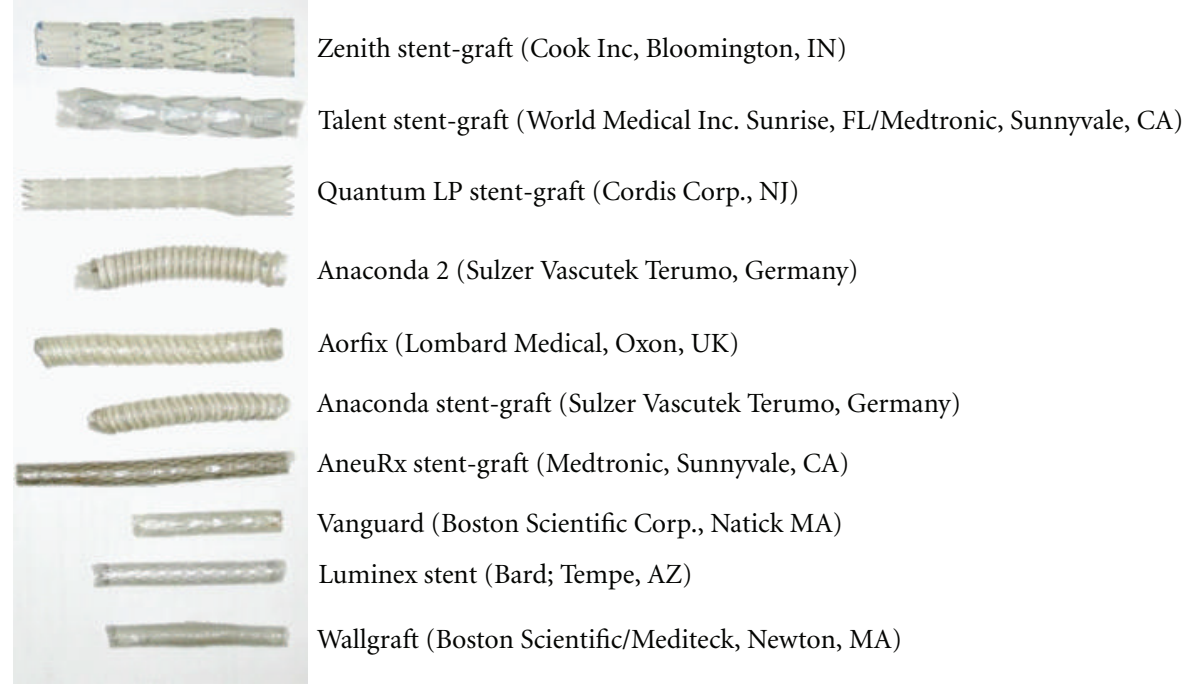

FigurE 17: Example of stent-graft in NiTi alloys [57].

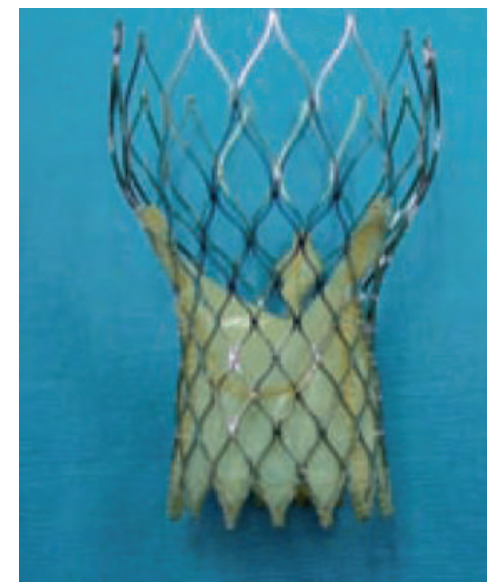

(a)

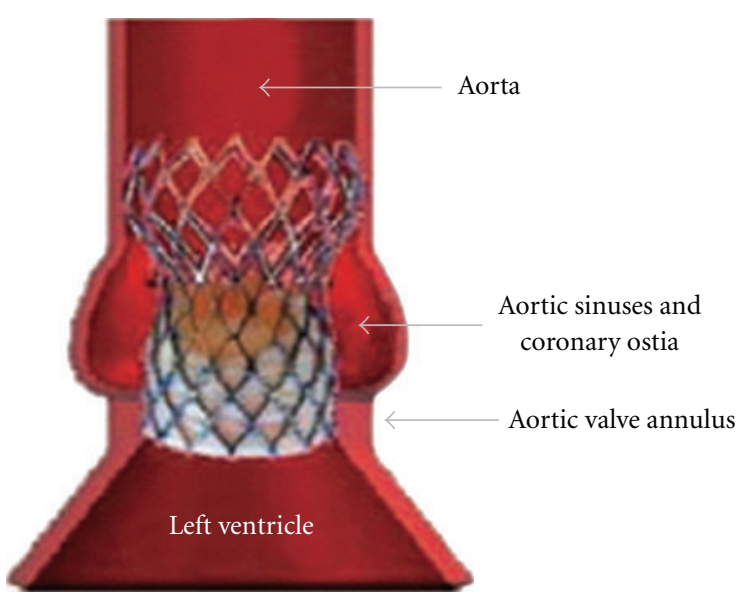

(b)

FIGURE 18: CoreValve aortic valve http://www.medtronic.com/corevalve/ous/index.html.

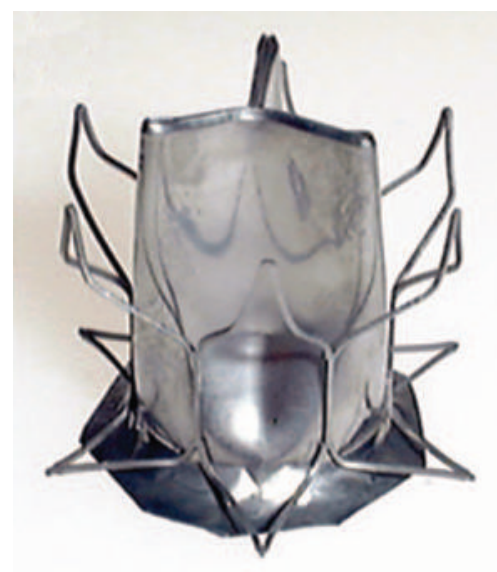

(a)

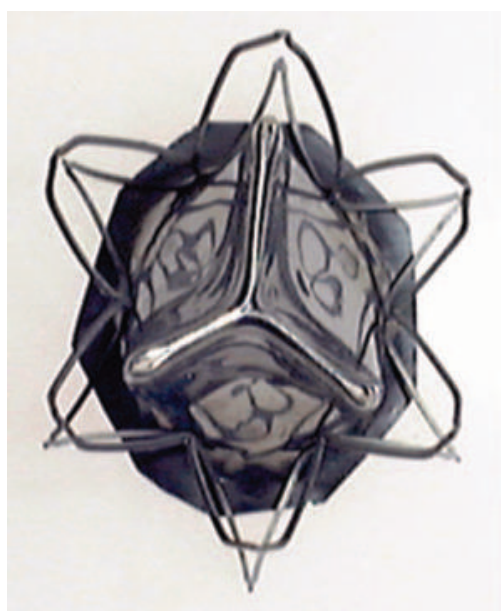

(b)

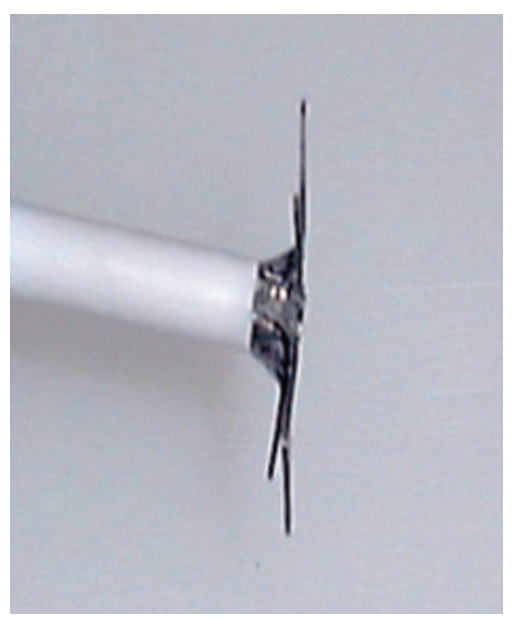

(c)

FIgURE 19: Percutaneous aortic valve realized with eNiTinol membranes and NiTi alloy stent [60]. 


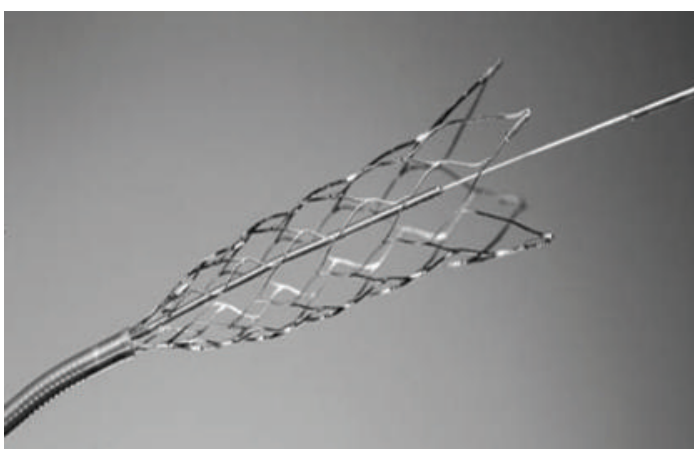

(a)

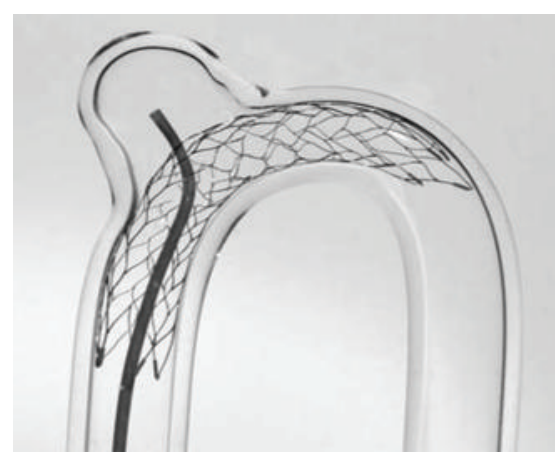

(b)

Figure 20: NiTi self-expandable neurosurgical stent (Enterprise Vascular Reconstruction Device; Cordis Corp., Miami Lakes, FL).

these reasons, great efforts are currently directed to a more rigorous understanding of NiTi fatigue behavior and to the design of NiTi medical devices that are more fatigue resistant. For sure, this is an area that will attract a good deal of research in the next feature.

\section{SMA Applications in the Neurosurgical Field}

Nowadays, NiTi alloys in the neurosurgical field [64] are used for producing three types of devices: (1) coils, (2) stents and (3) microguidewires.

Coils are devices used for the treatment of cerebral aneurysms, which are localized dilations of the intracranial arteries. Although the aneurysm may remain silent and without any symptom, peculiar attention has to be paid to its evolution in time, and treatment to be applied for avoiding rupture. Indeed, aneurysm rupture and consequently cerebral hemorrhage are among the principal causes of death in the Occidental countries. Coils are wires that are positioned into the aneurysm as a ball to induce clotting or thrombotic reaction within the aneurysm that, if successful, will eliminate the risk of rupture. Coils are generally made of platinum. However, a coil made with a mixture of platinum and NiTi has been recently produced (ev3 Neurovascular, Irvine, CA); the NiTi content seems to result in less stretching and better resistance to compaction with respect to traditional platinum coils.

Stents are also used for the treatment of intracranial atherosclerotic disease. The stent treatment aims to recover the original blood flow where there is a narrowed lumen. The major difficulty of the treatment is allowing the navigation of the system stent + catheter, which is relatively rigid, through tortuous anatomy up to the cerebral vessel. For this reason, SMA self-expandable stents are preferred over classical stents in stainless steel or Cr-Co alloy. Moreover, the wide plateau characterizing the NiTi mechanical hysteresis allows control of the forces exerted by the stent on the vessel wall. Stents (Figure 20) are also used as an assisting device for the endovascular coiling of intracranial aneurysms, in particular when the aneurysm has a large neck. Indeed, after the positioning of the coil into the aneurysm, a stent is released in the corresponding zone of the artery to maintain the coil in the correct place.

Moreover, microguidewires used for stent positioning may be made of NiTi with the advantage of obtaining a higher strain recovery and torsion resistance as well as a better stress distribution (due to the plateau in the stress-strain curve), which reduces the guidewire bending problems.

\section{Other Applications}

The use of NiTi self-expandable stents is not limited to the vascular and neurosurgical fields: they are also used for the treatment of biliary obstruction [65-67], of tracheal stenosis $[68,69]$, and of esophageal [70-72], rectosigmoidal [73], prostatic [74], and urethral $[75,76]$ strictures. In these cases, the stent is often covered by a polymeric material to completely replace the conduit (stent-graft).

Pseudoelasticity of SMA is also used for laparoscopic inguinal hernioplasty [77] as well as for producing wires for suture [78]. Shape memory effect is also exploited for stapes prosthesis [79], colonic anastomosis [80, 81], and expansion of soft tissue [82].

\section{Surgical Instruments}

The ability of SMA to remember highly deformed shapes and the presence of the plateau in the stress-strain curve, which assures a limitation in the force transmitted by the device thereby avoiding excessive damage of the tissues, has allowed the production of effective, mini-invasive surgical instruments, which are useful in many interventional and endoscopic procedures. The principal applications for surgical instruments are: guidewires, baskets for retrieval of calculi into kidney and bladder [83], catheters, snares [84, 85], and devices for laparoscopy.

\section{Conclusions}

Shape memory alloys, and in particular NiTi alloys, are characterized by two unique behaviors, which are thermally or mechanically activated: the shape memory effect and 
pseudoelastic effect. These behaviors, due to the peculiar crystallographic structure of the alloys, assure the recovery of the original shape even after large deformations and the maintenance of a constant applied force in correspondence to significant displacements. These properties, joined with good corrosion and fatigue resistance, biological and magnetic resonance compatibility, and optimal bending resistance, explain the large diffusion of SMA in the production of biomedical devices in the last 20 years.

The most promising field of SMA applications is probably related to the development of ever less invasive medical procedures. The exploitation of NiTi alloy properties has allowed a strong improvement in mini-invasive techniques in the last years. However, there is still a lot of room for new ideas able to enlarge the range of SMA applications or to optimize the existing SMA devices. There are different aspects that can be approached to develop or improve an NiTi medical product: a new design can be studied, a new alloy can be developed (changing the composition of nickel and titanium or alloying the nickel-titanium with other elements), melting practices can be improved, and heat treatment and mechanical processing of the alloy can be optimized. In a recent paper [86], it has been shown how (i) alloying the nickel-titanium with ternary elements may widen the pseudoelastic temperature operating window, maximize/minimize the stress-strain hysteresis, and improve the radiopacity of an NiTi alloy intraluminal device; (ii) limiting to less than $30 \%$ the final cold work step may improve the NiTi alloy fatigue lifetime by about 37\%; (iii) performing local selective and differential thermomechanical treatments may give different physical properties in different portions of a NiTi alloy medical device in order to improve its performance under expected operating conditions. These results underline an important aspect related to biomedical applications of shape memory alloys: the complexity of the material and application requires a strict collaboration between clinicians, engineers, physicists, and chemists for accurately defining the problem, finding the best solution in terms of device design, and, accordingly, optimizing the NiTi alloy properties.

\section{Acknowledgment}

The authors would like to thank Dr. Massimo Barbieri of the Technology Transfer Office of the Politecnico di Milano for the patent search.

\section{References}

[1] T. W. Duerig, K. N. Melton, D. Stöckel, and C. M. Wayman, Engineering Aspects of Shape Memory Alloys, ButterworthHeinemann, London, UK, 1990.

[2] Proceedings of the 1stInternational Conference on Shape Memory and Superelastic Technologies, A. R. Pelton, D. Hodgson, and T. Duerig, Eds., Asilomar, Calif, USA, 1995.

[3] Proceedings of the 2nd International Conference on Shape Memory and Superelastic Technologies, A. R. Pelton, D. Hodgson, and T. Duerig, Eds., Asilomar, Calif, USA, 1997.
[4] T. Duerig, A. Pelton, and D. Stöckel, "An overview of nitinol medical applications," Materials Science and Engineering A, vol. 273-275, pp. 149-160, 1999.

[5] C. D. J. Barras and K. A. Myers, "Nitinol—its use in vascular surgery and other applications," European Journal of Vascular and Endovascular Surgery, vol. 19, no. 6, pp. 564-569, 2000.

[6] D. Tarniţă, D. N. Tarniţă, N. Bîzdoacǎ, I. Mîndrilǎ, and M. Vasilescu, "Properties and medical applications of shape memory alloys," Romanian Journal of Morphology and Embryology, vol. 50, no. 1, pp. 15-21, 2009.

[7] Proceedings of the 3rd International Conference on Shape Memory and Superelastic Technologies, S. M. Russel and A. R. Pelton, Eds., Asilomar, Calif, USA, 2000.

[8] H. Funakubo, Shape Memory Alloys, Gordon and Breach Science Publishers, New York, NY, USA, 1987.

[9] C. M. Wayman, "Shape memory and related phenomena," Progress in Materials Science, vol. 36, no. 1, pp. 203-224, 1992.

[10] K. Otsuka and C. M. Wayman, Shape Memory Materials, Cambridge University Press, Cambridge, Mass, USA, 1998.

[11] K. Otsuka and X. Ren, "Physical metallurgy of Ti-Ni-based shape memory alloys," Progress in Materials Science, vol. 50, no. 5, pp. 511-678, 2005.

[12] T. W. Duerig, K. N. Pelton, and D. Stöckel, "Superelastic nitinol for medical devices," Medical Plastics and Biomaterials, vol. 2, pp. 30-43, 1997.

[13] C. Trépanier, T. K. Leung, M. Tabrizian et al., "Preliminary investigation of the effects of surface treatments on biological response to shape memory NiTi stents," Journal of Biomedical Materials Research, vol. 48, no. 2, pp. 165-171, 1999.

[14] B. Thierry, Y. Merhi, L. Bilodeau, C. Trépanier, and M. Tabrizian, "Nitinol versus stainless steel stents: acute thrombogenicity study in an ex vivo porcine model," Biomaterials, vol. 23, no. 14, pp. 2997-3005, 2002.

[15] J. Ryhanen, Biocompatibility evaluation of nickel-titanium shape-memory metal alloy, Ph.D. dissertation, University of Oulu, Department of Surgery, Oulu, Finlandia, 1999.

[16] A. Holton, E. Walsh, A. Anayiotos, G. Pohost, and R. Venugopalan, "Comparative MRI compatibility of 316L stainless steel alloy and nickel-titanium alloy stents," Journal of Cardiovascular Magnetic Resonance, vol. 4, no. 4, pp. 423-430, 2002.

[17] S. A. Shabalovskaya, "On the nature of the biocompatibility and on medical applications of NiTi shape memory and superelastic alloys," Bio-Medical Materials and Engineering, vol. 6, no. 4, pp. 267-289, 1996.

[18] P. Poncin, C. Millet, J. Chevy, and J. L. Proft, "Comparing and optimizing Co-Cr tubing for stent applications," in Proceedings of the Materials and Processes for Medical Devices Conference, pp. 279-283, August 2004.

[19] G. F. Andreasen and T. B. Hilleman, "An evaluation of 55 cobalt substituted Nitinol wire for use in orthodontics," The Journal of the American Dental Association, vol. 82, no. 6, pp. 1373-1375, 1971.

[20] L. Torrisi, "The NiTi superelastic alloy application to the dentistry field," Bio-Medical Materials and Engineering, vol. 9, no. 1, pp. 39-47, 1999.

[21] G. Airoldi, G. Riva, and M. Vanelli, "Superelasticity and shapememory effect in Ni-Ti orthodontic wires," in Proceedings of the International Conference on Martensitic Transformations (ICOMAT'95), 1995.

[22] S. Idelsohn, J. Peña, D. Lacroix, J. A. Planell, F. J. Gil, and A. Arcas, "Continuous mandibular distraction osteogenesis using superelastic shape memory alloy (SMA)," Journal of Materials Science, vol. 15, no. 4, pp. 541-546, 2004. 
[23] L. Torrisi and G. Di Marco, "Physical characterization of endodontic instruments in NiTi alloy," in Proceedings of the International Symposium on Shape Memory Materials, Materials Science Forum, vol. 327, pp. 75-78, 2000.

[24] P. Parashos and H. H. Messer, "The diffusion of innovation in dentistry: a review using rotary nickel-titanium technology as an example," Oral Surgery, Oral Medicine, Oral Pathology, Oral Radiology and Endodontology, vol. 101, no. 3, pp. 395401, 2006.

[25] B. Sattapan, J. E. Palamara, and H. H. Messer, "Torque during canal instrumentation using rotary nickel-titanium files," Journal of Endodontics, vol. 26, no. 3, pp. 156-160, 2000.

[26] K. R. Dai, X. K. Hou, Y. H. Sun, R. G. Tang, S. J. Qiu, and C. $\mathrm{Ni}$, "Treatment of intra-articular fractures with shape memory compression staples," Injury, vol. 24, no. 10, pp. 651-655, 1993.

[27] Z. Laster, A. D. MacBean, P. R. Ayliffe, and L. C. Newlands, "Fixation of a frontozygomatic fracture with a shape-memory staple," British Journal of Oral and Maxillofacial Surgery, vol. 39, no. 4, pp. 324-325, 2001.

[28] M. A. Schmerling, M. A. Wilkor, A. E. Sanders, and J. E. Woosley, "A proposed medical application of the shape memory effect: an Ni-Ti Harrington rod for treatment of scoliosis," Journal of Biomedical Materials Research, vol. 10, pp. 879-902, 1976.

[29] J. O. Sanders, A. E. Sanders, R. More, and R. B. Ashman, "A preliminary investigation of shape memory alloys in the surgical correction of scoliosis," Spine, vol. 18, no. 12, pp. 1640-1646, 1993.

[30] D. Wever, J. Elstrodt, A. Veldhuizen, and J. Horn, "Scoliosis correction with shape-memory metal: results of an experimental study," European Spine Journal, vol. 11, no. 2, pp. 100106, 2002.

[31] R. Contro, V. Dallolio, G. Franzoso, D. Gastaldi, and P. Vena, "Biomechanical study of a pathologic lumbar functional spinal unit and a possible surgical treatment through the implant of an interspinous device," in Biomechanics Applied to Computer Assisted Surgery, Y. Payan, Ed., pp. 39-52, Research Signpost, Trivandrum, India, 2005.

[32] S. Kujala, J. Ryhänen, T. Jämsä et al., "Bone modeling controlled by a nickel-titanium shape memory alloy intramedullary nail," Biomaterials, vol. 23, no. 12, pp. 25352543, 2002.

[33] M. Coati, G. Marazzi, G. Marini, L. Rossi, L. Rossi, and D. Venturini, Intramedullary Nail Comprising Elements of Shape-Memory Material, United States Patent Application Publication, 2008.

[34] L. G. Machado and M. A. Savi, "Medical applications of shape memory alloys," Brazilian Journal of Medical and Biological Research, vol. 36, no. 6, pp. 683-691, 2003.

[35] S. Abkowitz, J. M. Siergiej, and R. R. Regan, "Titanium-nickel alloy manufacturing methods," United States Patent Office Patent no. 3,700,434, 1969.

[36] S. A. Shabalovskaya, "Surface, corrosion and biocompatibility aspects of Nitinol as an implant material," Bio-Medical Materials and Engineering, vol. 12, no. 1, pp. 69-109, 2002.

[37] S. Shabalovskaya, J. Ryhanen, and L. H. Yahia, "Bioperformance of nitinol: surface tendencies," Shape-Memory Alloy and Its Application, vol. 394, pp. 131-138, 2001.

[38] A. Bansiddhi, T. D. Sargeant, S. I. Stupp, and D. C. Dunand, "Porous NiTi for bone implants: a review," Acta Biomaterialia, vol. 4, no. 4, pp. 773-782, 2008.
[39] C. E. Wen, J. Y. Xiong, Y. C. Li, and P. D. Hodgson, "Porous shape memory alloy scaffolds for biomedical applications: a review," Physica Scripta, vol. 39, Article ID 014070, 2010.

[40] F. Likibi, M. Assad, C. Coillard, G. Chabot, and C. H. Rivard, "Bone integration and apposition of porous and non porous metallic orthopaedic biomaterials," Annales de Chirurgie, vol. 130, no. 4, pp. 235-241, 2005.

[41] I. P. Lipscomb and L. D. M. Nokes, The Application of Shape Memory Alloys in Medicine, Paston Press Ltd, Norfolk, Va, USA, 1996.

[42] M. Simon, R. Kaplan, E. Salzman, and D. Freiman, "A vena cava filter using thermal shape memory alloy: experimental aspects," Radiology, vol. 125, no. 1, pp. 89-94, 1977.

[43] E. Engmann and M. R. Asch, "Clinical experience with the antecubital Simon nitinol IVC filter," Journal of Vascular and Interventional Radiology, vol. 9, no. 5, pp. 774-778, 1998.

[44] P. A. Poletti, C. D. Becker, L. Prina et al., "Long-term results of the Simon nitinol inferior vena cava filter," European Radiology, vol. 8, no. 2, pp. 289-294, 1998.

[45] M. R. Asch, "Initial experience in humans with a new retrievable inferior vena cava filter," Radiology, vol. 225, no. 3, pp. 835-844, 2002.

[46] E. Bruckheimer, A. G. Judelman, S. D. Bruckheimer, I. Tavori, G. Naor, and B. T. Katzen, "In vitro evaluation of a retrievable low-profile nitinol vena cava filter," Journal of Vascular and Interventional Radiology, vol. 14, no. 4, pp. 469-474, 2003.

[47] B. D. Thanopoulos, C. V. Laskari, G. S. Tsaousis, A. Zarayelyan, A. Vekiou, and G. S. Papadopoulos, "Closure of atrial septal defects with the amplatzer occlusion device: preliminary results," Journal of the American College of Cardiology, vol. 31, no. 5, pp. 1110-1116, 1998.

[48] K. C. Chan, M. J. Godman, K. Walsh, N. Wilson, A. Redington, and J. L. Gibbs, "Transcatheter closure of atrial septal defect and interatrial communications with a new self expanding nitinol double disc device (Amplatzer septal occluder): multicentre UK experience," Heart, vol. 82, no. 3, pp. 300-306, 1999.

[49] K. P. Walsh and I. M. Maadi, "The Amplatzer septal occluder," Cardiology in the Young, vol. 10, no. 5, pp. 493-501, 2000.

[50] S. Tyagi, S. Singh, S. Mukhopadhyay, and U. A. Kaul, "Selfand balloon-expandable stent implantation for severe native coarctation of aorta in adults," American Heart Journal, vol. 146, no. 5, pp. 920-928, 2003.

[51] A. J. Carter, D. Scott, J. R. Laird et al., "Progressive vascular remodeling and reduced neointimal formation after placement of a thermoelastic self-expanding nitinol stent in an experimental model," Catheterization and Cardiovascular Diagnosis, vol. 44, no. 2, pp. 193-201, 1998.

[52] G. Lewis, "Materials, fluid dynamics, and solid mechanics aspects of coronary artery stents: a state-of-the-art review," Journal of Biomedical Materials Research. Part B, vol. 86, no. 2, pp. 569-590, 2008.

[53] K. A. Hausegger, A. H. Cragg, J. Lammer et al., "Iliac artery stent placement: clinical experience with a nitinol stent," Radiology, vol. 190, no. 1, pp. 199-202, 1994.

[54] P. Carpenter, V. Rimbau, D. Raithel, and P. Peeters, "Challenging EVAR indication," Supplement to Endovascular Today, 2003.

[55] J. A. Kaufman, S. C. Geller, D. C. Brewster et al., "Endovascular repair of abdominal aortic aneurysms: current status and future directions," American Journal of Roentgenology, vol. 175, no. 2, pp. 289-302, 2000. 
[56] R. Uflacker and J. Robison, "Endovascular treatment of abdominal aortic aneurysms: a review," European Radiology, vol. 11, no. 5, pp. 739-753, 2001.

[57] M. Cattaneo, "Caratterizzazione biomeccanica sperimentale di stent-grafts," Tesi di Laurea, Politecnico di Milano, 2006.

[58] L. Coats and P. Bonhoeffer, "New percutaneous treatments for valve disease," Heart, vol. 93, no. 5, pp. 639-644, 2007.

[59] J. C. Laborde, D. V. M. Borensyein, D. V. M. Behr, B. Farah, and J. Fajadet, "Percutaneus implantation of the corevalve aortic valve prosthesis for patients presenting high risk for surgical valve replacement," Eurointerv, vol. 1, pp. 472-474, 2006.

[60] D. S. Levi, N. Kusnezov, and G. P. Carman, "Smart materials applications for pediatric cardiovascular devices," Pediatric Research, vol. 63, no. 5, pp. 552-558, 2008.

[61] A. R. Pelton, V. Schroeder, M. R. Mitchell, X. Y. Gong, M. Barney, and S. W. Robertson, "Fatigue and durability of Nitinol stents," Journal of the Mechanical Behavior of Biomedical Materials, vol. 1, no. 2, pp. 153-164, 2008.

[62] D. Allie, C. Hebert et al., "Nitinol stent fractures in the SFA," Endovascular Today, pp. 22-34, 2004.

[63] N. B. Morgan, "Medical shape memory alloy applicationsthe market and its products," Materials Science and Engineering $A$, vol. 378, no. 1-2, pp. 16-23, 2004.

[64] D. J. Hoh, B. L. Hoh, A. P. Amar, and M. Y. Wang, "Shape memory alloys: metallurgy, biocompatibility, and biomechanics for neurosurgical applications," Neurosurgery, vol. 64, no. 5, pp. 199-214, 2009.

[65] P. H. P. Davids, A. K. Groen, E. A. J. Rauws, G. N. J. Tytgat, and K. Huibregtse, "Randomised trial of self-expanding metal stents versus polyethylene stents for distal malignant biliary obstruction," Lancet, vol. 340, no. 8834-8835, pp. 1488-1492, 1992.

[66] P. Rossi, M. Bezzi, M. Rossi et al., "Metallic stents in malignant biliary obstruction: results of a multicenter European study of 240 patients," Journal of Vascular and Interventional Radiology, vol. 5, no. 2, pp. 279-285, 1994.

[67] M. Smits, K. Huibregtse, and G. Tytgat, "Results of the new nitinol self-expandable stents for distal biliary strictures," Endoscopy, vol. 27, no. 7, pp. 505-508, 1995.

[68] I. Vinograd, B. Klin, T. Brosh, M. Weinberg, Y. Flomenblit, and Z. Nevo, "A new intratracheal stent made from nitinol, an alloy with 'shape memory effect," Journal of Thoracic and Cardiovascular Surgery, vol. 107, no. 5, pp. 1255-1261, 1994.

[69] K. Yanagihara, H. Mizuno, H. Wada, and S. Hitomi, "Tracheal stenosis treated with self-expanding nitinol stent," Annals of Thoracic Surgery, vol. 63, no. 6, pp. 1786-1790, 1997.

[70] W. Cwikiel, R. Willen, H. Stridbeck, R. Lillo-Gil, and C. S. Von Holstein, "Self-expanding stent in the treatment of benign esophageal strictures: experimental study in pigs and presentation of clinical cases," Radiology, vol. 187, no. 3, pp. 667-671, 1993.

[71] M. Pocek, F. Maspes, S. Masala et al., "Palliative treatment of neoplastic strictures by self-expanding nitinol Strecker stent," European Radiology, vol. 6, no. 2, pp. 230-235, 1996.

[72] C. E. Angueira and S. C. Kadakia, "Esophageal stents for inoperable esophageal cancer: which to use?" American Journal of Gastroenterology, vol. 92, no. 3, pp. 373-376, 1997.

[73] J. Tack, A. M. Gevers, and P. Rutgeerts, "Self-expandable metallic stents in the palliation of rectosigmoidal carcinoma: a follow-up study," Gastrointestinal Endoscopy, vol. 48, no. 3, pp. 267-271, 1998.
[74] H. W. Gottfried, R. Gnann, E. Brandle, R. Bachor, J. E. Gschwend, and K. Kleinschmidt, "Treatment of high-risk patients with subvesical obstruction from advanced prostatic carcinoma using a thermosensitive mesh stent," British Journal of Urology, vol. 80, no. 4, pp. 623-627, 1997.

[75] D. Yachia, "The use of urethral stents for the treatment of urethral strictures," Annales d'Urologie, vol. 27, no. 4, pp. 245250, 1993.

[76] K. Mori, S. Okamoto, and M. Akimoto, "Placement of the urethral stent made of shape memory alloy in management of benign prostatic hypertrophy for debilitated patients," Journal of Urology, vol. 154, no. 3, pp. 1065-1068, 1995.

[77] J. M. Himpens, "Laparoscopic inguinal hernioplasty-repair with a conventional vs a new self-expandable mesh," Surgical Endoscopy, vol. 7, no. 4, pp. 315-318, 1993.

[78] S. Kujala, A. Pajala, M. Kallioinen, A. Pramila, J. Tuukkanen, and J. Ryhänen, "Biocompatibility and strength properties of nitinol shape memory alloy suture in rabbit tendon," Biomaterials, vol. 25, no. 2, pp. 353-358, 2004.

[79] G. P. Rajan, R. H. Eikelboom, K. S. Anandacoomaraswamy, and M. D. Atlas, "In vivo performance of the nitinol shapememory stapes prosthesis during hearing restoration surgery in otosclerosis: a first report," Journal of Biomedical Materials Research. Part B, vol. 72, no. 2, pp. 305-309, 2005.

[80] I. L. Nudelman, V. Fuko, F. Greif, and S. Lelcuk, "Colonic anastomosis with the nickel-titanium temperature-dependent memory-shape device," American Journal of Surgery, vol. 183, no. 6, pp. 697-701, 2002.

[81] C. Song, T. Frank, and A. Cuschieri, "Shape memory alloy clip for compression colonic anastomosis," Journal of Biomechanical Engineering, vol. 127, no. 2, pp. 351-354, 2005.

[82] R. K. Khouri and L. L. C. Brava, "Method and apparatus for expanding soft tissue with shape memory alloys," United States Patent no. US6478656B1, 2002.

[83] J. Kourambas, F. C. Delvecchio, R. Munver, and G. M. Preminger, "Nitinol stone retrieval-assisted ureteroscopic management of lower pole renal calculi," Urology, vol. 56, no. 6, pp. 935-939, 2000.

[84] S. Cekirge, J. P. Weiss, R. G. Foster, H. L. Neiman, and G. K. McLean, "Percutaneous retrieval of foreign bodies: experience with the nitinol Goose Neck snare," Journal of Vascular and Interventional Radiology, vol. 4, no. 6, pp. 805-810, 1993.

[85] W. Y. Wang, S. G. Cooper, and S. C. Eberhardt, "Use of a nitinol gooseneck snare to open an incompletely expanded over- the-wire stainless steel Greenfield filter," American Journal of Roentgenology, vol. 172, no. 2, pp. 499-500, 1999.

[86] A. Biscarini, G. Mazzolai, and A. Tuissi, "Enhanced nitinol properties for biomedical applications," Recent Patents on Biomedical Engineering, vol. 1, pp. 180-196, 2008. 

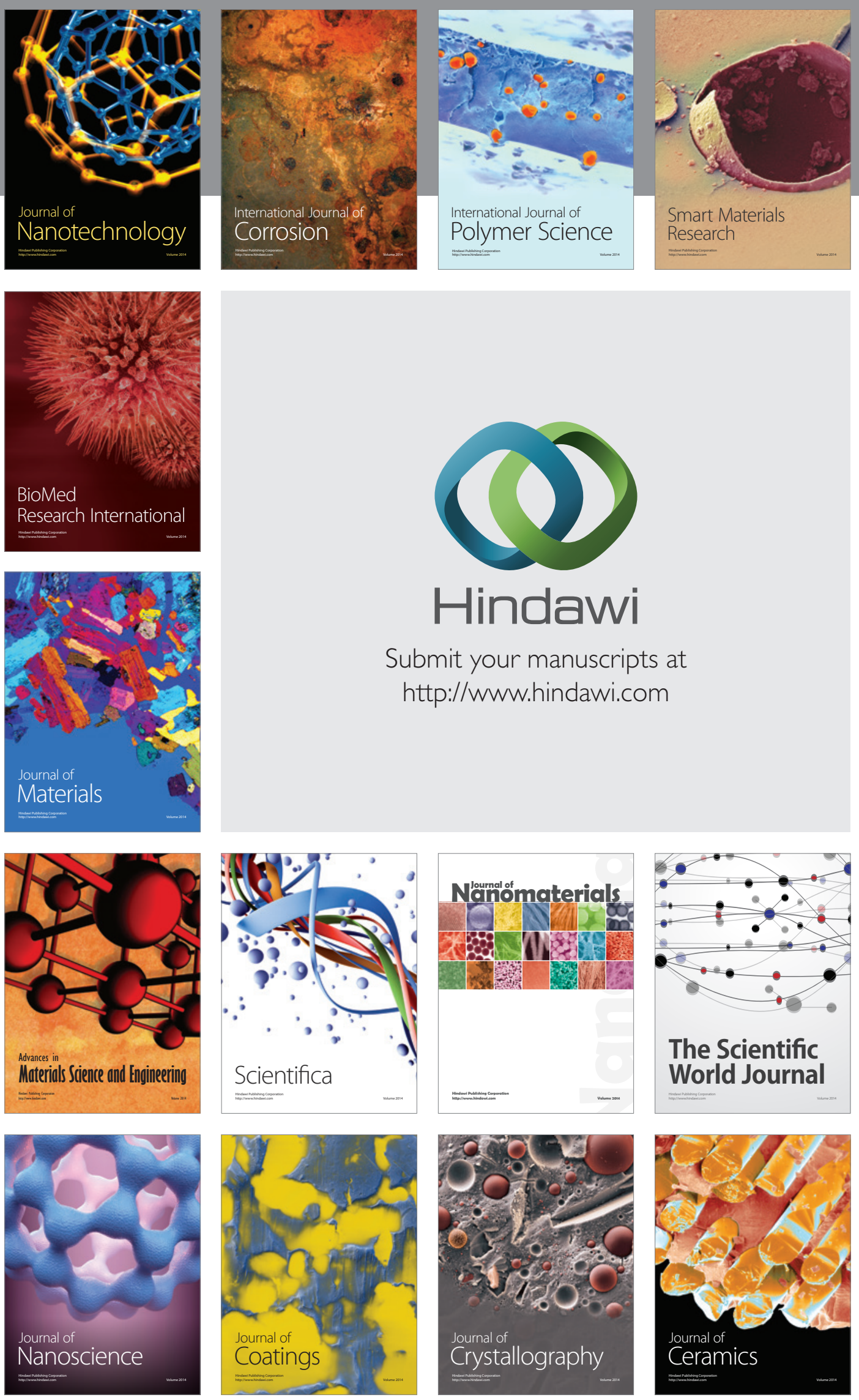

The Scientific World Journal

Submit your manuscripts at

http://www.hindawi.com

\section{World Journal}

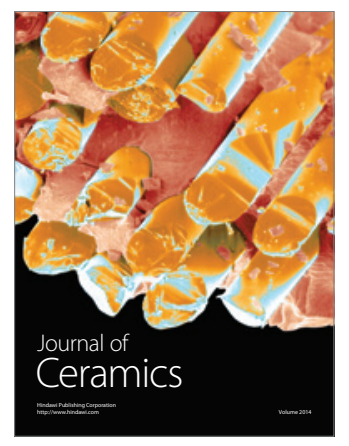

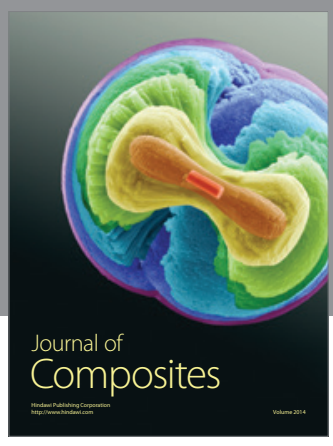
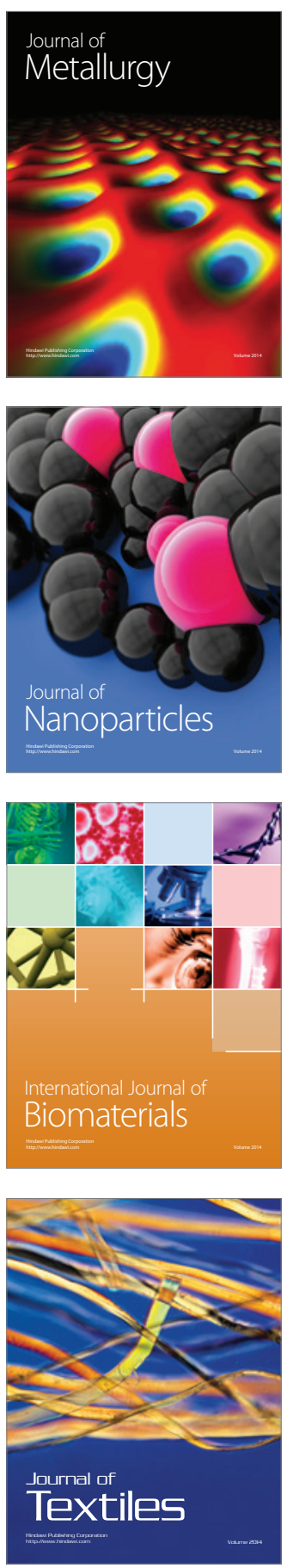